\title{
ВОПРОСЫ СОВЕРШЕНСТВОВАНИЯ НАЛОГООБЛОЖЕНИЯ ТРУДОВЫХ ДОХОДОВ НЕРЕЗИДЕНТОВ РОССИЙСКОЙ ФЕДЕРАЦИИ
}

\author{
(c) 2018 Куликова Ирина Владимировна \\ кандидат экономических наук, доцент кафедры экономики и финансов \\ Алтайский филиал Российской академии народного хозяйства и государственной службы \\ при Президенте РФ \\ 656008, г. Барнаул, ул. Партизанская, д. 187 \\ E-mail: irenkulikova_82@mail.ru
}

В данной статье автором изложены результаты исследования налогообложения личных доходов налогоплательщиков - нерезидентов РФ. Обоснована необходимость восстановления прогрессивной шкалы налогообложения в отношении нерезидентов, доходы которых в настоящее время облагаются по ставке $13 \%$ согласно российскому законодательству. Разработана и апробирована четырехступенчатая шкала налогообложения физических лиц - нерезидентов РФ, которая позволяет, не только более равномерно распределять налоговую нагрузку между налогоплательщиками в зависимости от уровня доходов, но и соблюдать основной принцип налогообложения.

Ключевые слова: налоги, доходы налогоплательщиков, налог на доходы физических лиц, резиденты РФ, нерезиденты РФ, минимальный размер оплаты труда, ставки налога, прогрессивная шкала.

В современных условиях одним из важнейших вопросов социально-экономического развития страны и регионов является дефицит финансовых ресурсов. Налоговое регулирование, представляющее собой комплекс методов и инструментов налоговой политики, ориентированное на вмешательство государства в рыночную экономику для достижения желаемого уровня социально-экономического развития, должно способствовать решению выше обозначенной проблемы.

Налогообложение личных доходов физических лиц имеет место во всех зарубежных странах и занимает существенную долю в общей структуре доходов государственных бюджетов.

Регулирующая функция при высоких налогах и слаборазвитой экономике оказывает свое негативное влияние на социально-экономическое развитие общества, проявляющееся в существенном спаде производства, стремлении населения к сокрытию своих доходов (полностью или частично), что в конечном итоге может негативно сказаться на эффективности налоговой системы страны в целом.

Для экономики любого государства объективно серьезным испытанием является миграция трудовых ресурсов в поисках возможности трудоустройства, более благоприятных условий для ведения бизнеса, а также в связи с бегством из территорий зон военных действий и кон- фликтов [1].

Кроме того, в качестве причин привлечения иностранных работников к труду можно выделить: дефицит отечественных кадров, как с высоким, так и с низким уровнем квалификации, существенная разница между спросом и предложением по отдельным профессионально-квалификационным категориям работников.

Исследованию вопросов налогообложения личных доходов физических лиц в своих трудах уделяют такие экономисты как: Е.А.Гулак, И.Г. Гуляева [2], В.А. Корецкая-Гармаш, И.А. Майбуров [3], Л.И. Осипчук， В.Г. Пансков [4], В.Ф Шевцова и другие, однако, по-прежнему остаются малоизученными вопросы привлечения иностранной рабочей силы и обложение их трудовых доходов.

Согласно налоговому законодательству Российской Федерации существует деление иностранных физических лиц на группы в зависимости от наличия у них статуса налогового резидента РФ:

- налогоплательщиками-резидентами признаются находящиеся на территории Российской Федерации не менее 183 календарных дней в течение 12 месяцев следующих подряд не привязанных к календарному году;

- налогоплательщиками-нерезидентами признаются находящиеся на территории Российской Федерации менее 183 календарных 
дней в течение 12 месяцев следующих подряд и не привязанных к календарному году.

На постоянной основе налоговыми резидентами Российской Федерации будут признаваться (ст. 207 НК РФ) [5]:

- военнослужащие Российской Федерации, проходящие службу за ее пределами;

- представители органов государственной власти, местного самоуправления, находящиеся в командировке за пределами Российской Федерации.

Определение налогового статуса важно с точки зрения применения ставки налога на доходы физических лиц организациями-работодателями возможности использования налоговых вычетов (стандартных, социальных, имущественных, профессиональных). В соответствии с Письмом Минфина России от 26.07.2010 г. № 0304-08/8-165 налоговые вычеты в части налога на доходы физических лиц могут применяться иностранными гражданами к трудовым доходам только после получения ими статуса налогового резидента РФ.

Следует отметить, что налоговый статус налогоплательщика физического лица должен определяться на любой момент выплаты ему доходов работодателем.

Российские организации, именуемые налоговыми агентами (российские организации, иностранные организации и индивидуальные предприниматели), которые выплачивают налоговым резидентам и нерезидентам вознаграждение за исполнение трудовых обязанностей, выполнение работ, оказание услуг, налоговое законодательство обязывает исчислять, удерживать и перечислять в бюджет суммы налога на доходы физических лиц.
Как известно, если иное не предусмотрено международными соглашениями, то нерезиденты РФ уплачивают налог только с доходов, полученных на территории Российской Федерации (ст. 207, ст. 209 НК РФ).

Нормы ст. 224 НК РФ определяют общую ставку 13\% применительно ко всем доходам физических лиц, если иное не установлено данной статьей. Налоговая ставка устанавливается на уровне $30 \%$ в отношении доходов физических лиц, не имеющих статуса налогового резидента.

Стоит отметить, что при определенных обстоятельствах доходы нерезидентов - иностранных работников облагаются также по общей ставке $13 \%$ (табл. 1).

Порядок исчисления и уплаты налога на доходы физических лиц в случае, если иностранные граждане, прибыли из стран, не имеющих визового режима с Россией, и осуществляют трудовую деятельность по найму в российских организациях или у индивидуальных предпринимателей (или лиц, занимающихся частной практикой: нотариусов, адвокатов и др.) на основании патента регулируется ст. 227.1 НК РФ.

За период действия патента иностранные граждане ежемесячно уплачивают фиксированный размер авансовых платежей в сумме 1200 руб., которые подлежат корректировке с учетом размера коэффициента-дефлятора, установленного на календарный год, а также на региональный коэффициент, учитывающий особенности рынка труда соответствующего субъекта Российской Федерации (если не установлен, то принимается равным 1). Фиксированный авансовый платеж по НДФЛ вносится иностранным работником по месту осуществления своей трудовой деятельности на основании патента.

Таблица 1. Ставки, применяемые к трудовым доходам иностранных граждан на территории Российской Федерации (составлено автором)

\begin{tabular}{|c|l|}
\hline Ставка НДФЛ & \multicolumn{1}{|c|}{ Статус иностранного гражданина, осуществляющего трудовую деятельность } \\
\hline $30 \%$ & $\begin{array}{l}\text { - иностранные граждане-налоговые нерезиденты, прибывшие из стран, имеющих } \\
\text { визовый режим с Россией. } \\
\text { - доходы высококвалифицированных специалистов нерезидентов РФ, которые не } \\
\text { связаны с трудовой деятельностью. }\end{array}$ \\
\hline $13 \%$ & $\begin{array}{l}\text { - иностранные граждане-налоговые резиденты, прибывшие из стран, имеющих } \\
\text { визовый режим с Россией; } \\
\text { - иностранные граждане, прибывшие из стран, не имеющих визового режима с Рос- } \\
\text { сией, но осуществлящие трудовую деятельность на основании патента (ст. 227.1); } \\
\text { - иностранные граждане, являющиеся высококвалифицированными специалистами; } \\
\text { - иностранные граждане, прибывшие из стран-участниц ЕАЭС; } \\
\text { - иностранные граждане, получившие статус беженцев или временное убежище на } \\
\text { территории России. }\end{array}$ \\
\hline
\end{tabular}


Общая величина налога работодателем-налоговым агентом может быть скорректирована на сумму авансовых платежей, внесенных заблаговременно иностранным гражданином в рамках определенного налогового периода при наличии заявления налогоплательщика, документов, подтверждающих внесение указанных платежей и разрешения налогового органа на проведение такого перерасчета.

Рассмотрим порядок обложения доходов иностранных граждан, прибывших из стран-участниц Договора о Евразийском экономическом союзе (ЕАЭС). Указанный договор вступил в силу с 01.01.2015 года, странами-участницами которого в настоящее время являются: Российская Федерация, Беларусь, Казахстан, Республика Армения, Кыргызская Республика.

Положения статьи 73 Договора о ЕАЭС свидетельствуют, о том, что доходы налоговых резидентов (граждан Казахстана, Беларуси, Кыргызстана, Армении), получаемые в связи с осуществлением трудовых обязанностей по найму, начиная с первого дня их работы на территории Российской Федерации, будут облагаться по налоговой ставке $13 \%$, оформление разрешения на работу и патент не требуется.

Порядок обложения доходов иностранных граждан, которые прибыли из стран, имеющих визовый режим с Российской Федерацией, будет зависеть от их налогового статуса: к доходам нерезидентов применяется ставка - 30\%, к доходам резидентов $-13 \%$, кроме того, требуется оформление разрешения на работу.

Согласно ст. 13.2 Закона № 115-ФЗ «О правовом положении иностранных граждан в Российской Федерации» высококвалифицированным специалистом признается гражданин другого государства, обладающий опытом работы, навыками и результатами в определенной области деятельности, однако, обязательным критерием является минимальный размер вознаграждения, выплачиваемого работодателем, за выполнение трудовых функций в зависимости от рода деятельности (табл.2).

Следует отметить, что в Законе (ст. 13.2) прописаны сферы деятельности, куда иностранные граждане не могут привлекаться в качестве высококвалифицированных работников, например, религиозная деятельность, розничная торговля (за исключением руководящего состава).

Стоит обратить внимание на то, что согласно мнению Минфина России, изложенному в Письме от 08.06.2012 г. № 03-04-06/6-158 не все доходы высококвалифицированных специалистов нерезидентов РФ будут облагаться по ставке $13 \%$.

Так, трудовое законодательство (ст. 129 ТК РФ) определяет заработную плату - как вознаграждение за выполнение трудовых обязанностей в зависимости от квалификации сотрудника, сложности, объема, качества, условий труда, а также компенсационные и стимулирующие выплаты. Следовательно, такие выплаты высококвалифицированным специалистам как: возмещение аренды жилья, материальная по-

\section{Таблица 2. Критерии признания иностранного гражданина высококвалифицированным работником} (ст.13.2 Ф3 № 115-Ф3)

\begin{tabular}{|l|c|}
\hline \multicolumn{1}{|c|}{ Условия привлечения к труду } & Заработная плата \\
\hline $\begin{array}{l}\text { 1. Иностранцы - научные работники или преподаватели, осуществляю- } \\
\text { щие трудовую деятельность: в образовательных организациях высшего } \\
\text { образования; в государственных академиях наук и других подобных } \\
\text { организациях в промышленно-производственных, туристско-рекреаци- } \\
\text { онных, портовых особых экономических зонах; в организациях, осущест- } \\
\begin{array}{l}\text { вляющих свою деятельность в области информационных технологий при } \\
\text { соблюдении определенных условий. }\end{array}\end{array}$ & не менее 83500 руб. за месяц \\
\hline $\begin{array}{l}\text { 2. Иностранцы, привлеченные к трудовой деятельности в технико- } \\
\text { внедренческие особые экономические зоны. }\end{array}$ & не менее 58500 руб. в месяц \\
\hline $\begin{array}{l}\text { 3. Иностранцы - медицинские, педагогические или научные работники, } \\
\text { осуществляющие трудовую деятельность на территории международного } \\
\text { медицинского кластера. }\end{array}$ & не менее 1000 000 руб. за год \\
\hline $\begin{array}{l}\text { 4. Иностранцы, осуществляющие трудовую деятельность в инновацион- } \\
\text { ном центре «Сколково». }\end{array}$ & размер не учитывается \\
\hline $\begin{array}{l}\text { 5. Иностранцы, осуществляющие трудовую деятельность в организациях } \\
\text { на территории Республики Крым и г. Севастополя. }\end{array}$ & не менее 83500 руб. в месяц \\
\hline $\begin{array}{l}\text { 6. Иностранцы, осуществляющие трудовую деятельность на территории } \\
\text { Российской Федерации. }\end{array}$ & не менее 167000 руб. в месяц \\
\hline
\end{tabular}


мощь, оплата услуг добровольного страхования, ежемесячная компенсация расходов на питание, единовременная компенсация на обустройство при переезде в Российскую Федерацию и другие подлежать обложению налогом на доходы физических лиц уже по ставке $30 \%$.

На наш взгляд, особого внимания заслуживают вынужденные трудовые мигранты, такие как беженцы и переселенцы - лица, которые оказались в сложных жизненных обстоятельствах, сопряженных с угрозой здоровью и жизни. В соответствии с законами «О вынужденных переселенцах», «О беженцах», Постановлением Правительства Российской Федерации «О предоставлении временного убежища на территории Российской Федерации» государство берет на себя определенные обязательства в части обеспечения указанных лиц: единовременными денежными пособиями в размере не менее 100 руб. на каждого члена семьи; временным жильем; продуктами питания; коммунальными услугами; медицинской помощью и медицинскими препаратами; помощью при трудоустройстве.

Налоговое законодательство Российской Федерации предоставляет определенного рода преференции указанным выше лицам, так согласно п.3 ст. 224 НК РФ налоговая ставка устанавливается в размере $13 \%$ в отношении трудовых доходов:

- участников Государственной программы по оказанию содействия добровольному переселению в Российскую Федерацию соотечественников, проживающих за рубежом;

- иностранцев или лиц без гражданства, являющихся беженцами или получивших временное убежище на территории России.

Действующая с 2001 года и по настоящее время модель налогообложения с плоской шкалой без дифференциации по доходам резидентов и нерезидентов РФ является достаточно спорной.

Весомым аргументом в пользу возврата к прогрессивной шкале налогообложения личных доходов физических лиц является тот факт, что практически нигде за рубежом, за исключением стран постсоветского пространства (Беларусь, Румыния, Болгария и др.), не существует плоской шкалы по рассматриваемому налогу [6].

Представляется целесообразным восстановить прогрессивную шкалу налогообложения доходов нерезидентов РФ с учетом дифференциации доходов. Наряду с введением прогрессивной шкалы, по нашему мнению, следует предусмотреть необлагаемый минимум для работников с низким уровнем доходов, привязав его к кратности МРОТ, установленного на федеральном уровне (табл.3).

В качестве примера расчета сумм НДФЛ при рекомендуемой сложной прогрессивной шкале налогообложения был взят нерезидент РФ с доходами на уровне средней заработной платы по Алтайскому краю 23 тыс. руб. (табл.4) и нерезидент РФ с уровнем дохода 150 тыс. руб. в месяц (табл. 5).

Приведенные в таблицах расчеты наглядно демонстрируют, что при заработной плате 23 тыс. руб. в месяц уровень налоговая нагрузка на нерезидента РФ снижается на 5\%, а при доходе 150 тыс. руб. в месяц, напротив, существенно возрастает на $20 \%$.

Таким образом, применение рекомендуемой сложной прогрессивной шкалы налогообложения в отношении личных доходов нерезидентов, обеспечит более справедливое перераспределение налоговой нагрузки с учетом возможных доходов налогоплательщиков, что соответствует одному из важнейших принципов теории налогообложения.

Таблица 3. Прогрессивная шкала по налогу на доходы физических лиц - нерезидентов РФ в зависимости от уровня дохода

\begin{tabular}{|c|c|}
\hline Уровень дохода & Ставки \\
\hline До 20 МРОТ* & $12 \%$ \\
\hline От 20 до 50 МРОТ & $13 \%$ \\
\hline От 50 до 125 МРОТ & $13 \%+15 \%$ с суммы превышающей 50 МРОТ \\
\hline Свыше 125 МРОТ & $13 \%+15 \%$ с суммы превышающей 50 МРОТ +20\% суммы превышающей 125 МРОТ \\
\hline
\end{tabular}

* С 1 января 2019 года в Российской Федерации МРОТ составляет 11280 руб. в месяц 
Таблица 4. Экономический эффект при использовании сложной прогрессивной шкалы налогообложения по налогу на доходу физических лиц по отношению к нерезиденту РФ

\begin{tabular}{|c|c|c|c|c|c|c|c|}
\hline \multirow{3}{*}{ Месяцы } & \multirow{3}{*}{$\begin{array}{c}\text { Доход } \\
\text { нарастаю- } \\
\text { щим итогом, } \\
\text { тыс. руб. }\end{array}$} & \multicolumn{3}{|c|}{ Рекомендуемая шкала } & \multicolumn{3}{|c|}{ Применяемая шкала } \\
\hline & & \multirow[b]{2}{*}{ Ставка\% } & \multicolumn{2}{|c|}{ Сумма налога, тыс. руб. } & \multirow[b]{2}{*}{ Ставка\% } & \multicolumn{2}{|c|}{ Сумма налога, тыс. руб. } \\
\hline & & & за месяц & $\begin{array}{c}\text { итого } \\
\text { с начала года }\end{array}$ & & за месяц & $\begin{array}{c}\text { итого } \\
\text { с начала года }\end{array}$ \\
\hline 1 & 23 & 12 & 2,8 & 2,8 & 13 & 3,0 & 3,0 \\
\hline 2 & 46 & 12 & 2,8 & 5,6 & 13 & 3,0 & 6,0 \\
\hline 3 & 69 & 12 & 2,8 & 8,4 & 13 & 3,0 & 9,0 \\
\hline 4 & 92 & 12 & 2,8 & 11,2 & 13 & 3,0 & 12,0 \\
\hline 5 & 115 & 12 & 2,8 & 14,0 & 13 & 3,0 & 15,0 \\
\hline 6 & 138 & 12 & 2,8 & 16,8 & 13 & 3,0 & 18,0 \\
\hline 7 & 161 & 12 & 2,8 & 19,6 & 13 & 3,0 & 21,0 \\
\hline 8 & 184 & 12 & 2,8 & 22,4 & 13 & 3,0 & 24,0 \\
\hline 9 & 207 & 12 & 2,8 & 25,2 & 13 & 3,0 & 27,0 \\
\hline 10 & 230 & 13 & 3,0 & 28,2 & 13 & 3,0 & 30,0 \\
\hline 11 & 253 & 13 & 3,0 & 31,2 & 13 & 3,0 & 33,0 \\
\hline 12 & 276 & 13 & 3,0 & 34,2 & 13 & 3,0 & 36,0 \\
\hline Итого & - & - & 34,2 & - & - & 36,0 & - \\
\hline
\end{tabular}

Таблица 5. Экономический эффект при использовании сложной прогрессивной шкалы налогообложения по налогу на доходы физических лиц по отношению к нерезиденту РФ

\begin{tabular}{|c|c|c|c|c|c|c|c|}
\hline \multirow{3}{*}{ Месяцы } & \multirow{3}{*}{$\begin{array}{c}\text { Доход } \\
\text { нарастаю- } \\
\text { щим итогом, } \\
\text { тыс. руб. }\end{array}$} & \multicolumn{3}{|c|}{ Рекомендуемая шкала } & \multicolumn{3}{|c|}{ Применяемая шкала } \\
\hline & & \multirow[b]{2}{*}{ Ставка\% } & \multicolumn{2}{|c|}{ Сумма налога, тыс. руб. } & \multirow[b]{2}{*}{ Ставка\% } & \multicolumn{2}{|c|}{ Сумма налога, тыс. руб. } \\
\hline & & & за месяц & $\begin{array}{c}\text { итого } \\
\text { с начала года }\end{array}$ & & за месяц & $\begin{array}{c}\text { итого } \\
\text { с начала года }\end{array}$ \\
\hline 1 & 150 & 12 & 18,0 & 18,0 & 13 & 19,5 & 19,5 \\
\hline 2 & 300 & 13 & 19,5 & 37,5 & 13 & 19,5 & 39,0 \\
\hline 3 & 450 & 13 & 19,5 & 57,0 & 13 & 19,5 & 58,5 \\
\hline 4 & 600 & 15 & 22,5 & 79,5 & 13 & 19,5 & 78,0 \\
\hline 5 & 750 & 15 & 22,5 & 102,0 & 13 & 19,5 & 97,5 \\
\hline 6 & 900 & 15 & 22,5 & 124,5 & 13 & 19,5 & 117 \\
\hline 7 & 1050 & 15 & 22,5 & 147,0 & 13 & 19,5 & 136,5 \\
\hline 8 & 1200 & 15 & 22,5 & 169,5 & 13 & 19,5 & 156,0 \\
\hline 9 & 1350 & 15 & 22,5 & 192,0 & 13 & 19,5 & 175,5 \\
\hline 10 & 1500 & 20 & 30,0 & 222,0 & 13 & 19,5 & 195,0 \\
\hline 11 & 1650 & 20 & 30,0 & 252,0 & 13 & 19,5 & 214,5 \\
\hline 12 & 1800 & 20 & 30,0 & 282,0 & 13 & 19,5 & 234,0 \\
\hline Итого & - & - & 282,0 & - & - & 234,0 & - \\
\hline
\end{tabular}

\section{Библиографический список}

1. Корецкая-Гармаш В.А. Российские реалии налогообложения иностранных работников на примере Свердловской области // Известия Иркутской государственной экономической академии (Байкальский государственный университет экономики и права). Т.6. 2015. № 3.

2. Гуляева И.Г., Няведомская А.И. Практика применения НДФЛ в России и зарубежом // Вестник Уральского института экономики, управления и права. 2017. № 2. С. 41-47. 
3. Налоговые реформы. Теория и практика: монография / под ред. И.А. Майбурова, Ю.Б. Иванова. Москва. 2012. $463 \mathrm{c}$.

4. Пансков В.Г. О проблемах налогообложения физических лиц // Финансы. 2008. № 1. С.28-33.

5. Налоговый кодекс Российской Федерации (часть вторая) URL: http://www.consultant.ru/document/cons_doc_ LAW_28165/

6. Шевцзова В.Ф., Гулак Е.А. О налоговом мониторинге нерезидентов-физических лиц // Дальневосточный аграрный вестник. 2015. 2(24). С. 69-78.

Поступила в редакцию 21.12.2018 